\title{
Size, survival and the potential for reproduction in transplants of Mazzaella splendens and M. linearis (Rhodophyta)
}

\author{
Frank J. Shaughnessy ${ }^{1, *}$, Robert E. DeWreede ${ }^{2}$ \\ ${ }^{1}$ Department of Biological Sciences, Humboldt State University, Arcata, California 95521, USA \\ ${ }^{2}$ Department of Botany, University of British Columbia, Vancouver, British Columbia V6T 1Z4, Canada
}

\begin{abstract}
Biomechanical models of red algae have been developed that make predictions about blade survivorship based on tissue strengths, drag coefficients, and blade surface areas. The first 2 objectives of the present field study were therefore to examine actual survivorship of genets (i.e. holdfast + blades) from wide- and narrow-bladed species of Mazzaella G. DeToni f., as well as to compare blade survivorship to predictions of their survival from a previous biomechanics study of the 2 species. The third and fourth objectives were, respectively, to determine the most frequent break location in the genet, and finally to ascertain if surviving blades are likely to be reproductive. Low intertidal transplant sites were established at a wave-sheltered site where the wide-bladed form of Mazzaella splendens (Setchell et Gardner) Fredericq occurs, and in a high wave impact habitat of the narrow-bladed Mazzaella linearis (Setchell et Gardner) Fredericq. Short and long blades size classes (SC1, SC2, respectively) were included for each species because separate population sampling established that SC1 blades are almost never reproductive, whereas SC2 blades are potentially reproductive. Within the high wave impact transplant site, genet survival of experimental (i.e. transplanted to site of the other species) M. splendens was initially lower than for control (i.e. transplanted within native site) $M$. linearis presumably due to drag on the larger $M$. splendens blades. As predicted by the biomechanics model, long blades of control $M$. linearis survive better than those of experimental $M$. splendens, but not as well as short blades of experimental $M$. splendens. However, the narrow blade of $M$. linearis allows it to reach a reproductively mature length, whereas the short, broken survivors of experimental M. splendens are not long enough to be reproductive. In the sheltered transplant site, genet survival for control $M$. splendens and experimental $M$. linearis was similar, but replicate $M$. linearis populations located higher in the intertidal were stressed (i.e. bleached) and more likely to die. Survivorship for SC2 blades of experimental $M$. linearis was not greater than SC2 blades of control $M$. splendens as predicted by the biomechanics model; survivorship of these 2 treatments was similar. For both species, the junction between the stipe and holdfast was rarely the most frequent break location as predicted by previous studies of Mazzaella and other red algae. We conclude that M. linearis is more likely to survive and become reproductive at high wave impact sites because its narrow blade can persist in the face of large hydrodynamic forces. In contrast, in a sheltered site the widebladed form of $M$. splendens is still at a hydrodynamic disadvantage relative to $M$. linearis, but $M$. splendens is able to survive long enough to produce wide, potentially reproductive blades because it is apparently more tolerant of abiotic conditions (e.g. high irradiance, desiccation) within these sites.
\end{abstract}

KEY WORDS: Biomechanics · Common garden · Mazzaella splendens · Mazzaella linearis · Reproduction · Survivorship Resale or republication not permitted without written consent of the publisher

\section{INTRODUCTION}

Biomechanical studies have helped to determine functions of morphological differences within and among taxa, as well as the consequences of functional differences to survivorship. A subset of these studies have focused on red algae in the families Gigartinaceae, which contains taxa such as Mazzaella G. 
DeToni f. and Chondrus Stackhouse, and the Petrocelidaceae with Mastocarpus Kützing (Hommersand et al. 1993). Gametophytes and sporophytes from the Gigartinaceae are comprised of perennial holdfasts with shorter-lived, perhaps annual blades, whereas this is only true for gametophytes in the Petrocelidaceae. Upright portions of genets (i.e. holdfast + blades) are either blades as in the case of Mazzaella splendens (Setchell et Gardner) Fredericq, or branched fronds such as those of Chondrus and Mastocarpus. Field tests using a spring scale attached to the middle of undamaged blades or fronds have shown that the junction between the stipe and holdfast (hereafter called the junction) is the most frequent break point (Carrington [= Bell] 1990, Shaughnessy et al. 1996). This is due to applied forces that concentrate tissue stresses at the narrowest part of the genet, which in the case of these red algae is the junction between the holdfast and stipe (Denny et al. 1989).

As blades and fronds increase in length, junction thickness does not, thus the upper limit of surface area (i.e. planform area) is set by the point at which hydrodynamic forces surpass junction break forces (Carrington 1990, Dudgeon \& Johnson 1992, Shaughnessy et al. 1996). Comparisons of junction break forces to estimates of hydrodynamic forces have produced predictions of blade or frond survivorship. The hydrodynamic force experienced by an individual depends upon water velocity, and primarily the taxon-specific surface area and drag coefficient (Koehl 1986, Carrington 1990). In these biomechanical models, the probability of blade or frond survival therefore decreases as the estimated hydrodynamic force on a taxon approaches junction break forces of the taxon (Denny et al. 1985, Carrington 1990, Denny 1995, Shaughnessy et al. 1996, Blanchette 1997, Bell 1999). The overall purpose of the present study is therefore to field test survivorship predictions from a biomechanics model for 2 algae in this group, Mazzaella splendens, and M. linearis (Setchell et Gardner) Fredericq.

These 2 sister species have morphological differences that are correlated to low intertidal habitats that differ in the amount of wave energy they receive. Mazzaella splendens has a short, thin stipe and a wide blade at sheltered sites, but a narrower blade at sites with intermediate wave exposure. It also occurs subtidally, and from open coast to estuarine habitats. In contrast, $M$. linearis is only found in outer coast habitats subject to high wave impact and it has a longer, thicker stipe supporting the narrowest blade (Shaughnessy 1996). Differences in stipe and blade shape between $M$. linearis and the wide bladed form of $M$. splendens are not due to phenotypic plasticity, as they reproduce their original morphologies when regrown from holdfasts in reciprocal transplant sites (Shaughnessy 1994).
A biomechanics model for predicting blade survivorship was developed for Mazzaella splendens and $M$. linearis (Shaughnessy et al. 1996). When the total force required to break the junction between the stipe and holdfast was compared, it was found that the 2 species were not significantly different. Thus, since the primary determinant of drag is blade surface area, the significantly wider blades of $M$. splendens are the reason why its blades should always have a lower probability of survival than $M$. linearis blades of a similar length.

The first objective of the present study is to examine survivorship of Mazzaella linearis and the wide-bladed form of $M$. splendens at the level of the whole genet. Although the 2 species alternate with each other along the shoreline depending upon how rock topography affects wave energy, they do not occur in the same habitats (Shaughnessy 1996). Thus, using a transplant experiment, genet survivorship should be greatest for each species in its native habitat. The second objective directly addresses hypotheses about blade survival generated by the biomechanics model for M. splendens and M. linearis (Shaughnessy et al. 1996). They are as follows: (1) long (i.e. Size Class 2; SC2) blades of $M$. linearis should survive better than SC2 blades of $M$. splendens at the high impact site of $M$. linearis; (2) despite the fact that Barkely Sound populations of the 2 species do not occur in the same habitat, the model predicts that long $M$. linearis blades should not survive as well as short (i.e. SC1) blades of $M$. splendens at the high impact site; and (3) SC2 blades of $M$. linearis should survive better than SC2 blades of M. splendens at the sheltered site of $M$. splendens. It was not possible with our transplant experiment to know the cause of mortality for each genet and blade. However, knowing the intertidal location of each genet, its condition (i.e. blade size class, bleached or dark purple, broken or entire blade), and its fate did provide the basis for suggesting why mortality occurred. Our third objective was to determine the most frequent break location in the genet, which should be the junction (Carrington 1990, Shaughnessy et al. 1996). The last objective was to determine if surviving blades were long enough to be reproductive.

\section{MATERIALS AND METHODS}

Site description. Wizard Rocks in Barkley Sound $\left(48^{\circ} 50^{\prime} \mathrm{N}, 125^{\circ} 10^{\prime} \mathrm{W}\right)$, where only Mazzaella splendens occurs, and the outermost rocks of Prasiola Point, where only $M$. linearis occurs, were selected as common garden sites for these species (Fig. 1). Common gardens were situated within the naturally occurring intertidal ranges of each species and the surrounding 
community was cleared in only those areas where transplants were attached. The sheltered common garden at Wizard Rocks was located between 1.06 and $0.60 \mathrm{~m}$ above Lowest Normal Tide (LNT; Canadian Chart Datum). Qualitative observations across $2 \mathrm{yr}$ indicated that $M$. splendens was one of the numerically dominant algae in this vertical range along with the kelp Egregia menziesii (Turner) Areschoug and the red alga Prionitis lanceolata (Harvey) Harvey. The high wave impact site at Prasiola Point was located between 1.29 and $0.75 \mathrm{~m}$ above LNT, and Lessoniopsis littoralis (Tilden) Reinke was the only kelp in this zone, where it covered approximately 40 to $50 \%$ of the area. The underlying space was covered primarily by the gooseneck barnacle Polycipes polymerus Sowerby, the California mussel Mytilus californianus Conrad, and M. linearis.

Transplant sites. Vinyl covered metal mesh $(3.5 \mathrm{~mm}$ in diameter), cross-linked every $2.5 \mathrm{~cm} \times 5.0 \mathrm{~cm}$, was used as part of the transplant substratum (Fig. 2). This mesh is strong and yet malleable enough to bend with the rock topography. Mesh strips were cut so that each was $90.0 \mathrm{~cm}$ long by $7.5 \mathrm{~cm}$ wide, which allowed for 2 parallel rows of genets. Attachment sites were chosen where the entire mesh strip could be in contact with the rock substratum. Bolts were secured at each end of the strip, and a third bolt placed as close to the middle as possible. Holes for anchor (= wedge) bolts were made in the rock by using a pneumatic hammer/drill (Chicago Pneumatic 9AK Handrill) with a $9.4 \mathrm{~mm}$ carbide tipped bit; a SCUBA tank was used as an air source. Stainless steel anchor bolts $(12.7 \mathrm{~cm} \times$ $9.4 \mathrm{~mm}$ ) were then hammered into the drill holes.

Entire genets of Mazzaella splendens and M. linearis were haphazardly collected throughout the vertical range of each species, and these were transferred to flowing seawater tanks at the Bamfield Marine Station within $2 \mathrm{~h}$ of removal. Each mesh strip to be used for transplantation was allotted 36 genets (now considered a population) half of which were in size class 1 (i.e. SC1: 0.5 to $5.0 \mathrm{~cm}$ long including stipe length) and the other half in SC2 (i.e. $>5.0 \mathrm{~cm}$ ). Mean starting lengths for a subsample of transplanted genets were the following: M. splendens, $\mathrm{SC} 1=3.8 \mathrm{~cm}(\mathrm{n}=54, \mathrm{SD}=1.2), \mathrm{SC} 2=$ $19.0 \mathrm{~cm}(\mathrm{n}=54, \mathrm{SD}=5.5) ;$ M. linearis, $\mathrm{SC} 1=3.4 \mathrm{~cm}$ $(\mathrm{n}=54, \mathrm{SD}=1.3), \mathrm{SC} 2=18.5 \mathrm{~cm}(\mathrm{n}=54, \mathrm{SD}=4.0)$.

The basis for dividing blades in the transplant experiment into SC1 and SC2 came from a separate sampling of blades from natural populations of each species. Mazzaella splendens was collected from Wizard Rocks whereas $M$. linearis was sampled from Prasiola Point and Nudibranch Point (Fig. 1). Each site was sampled 10 times at regular intervals between May 1990 to October 1991. A transect with 35 randomly determined positions was placed in a Mazzaella zone

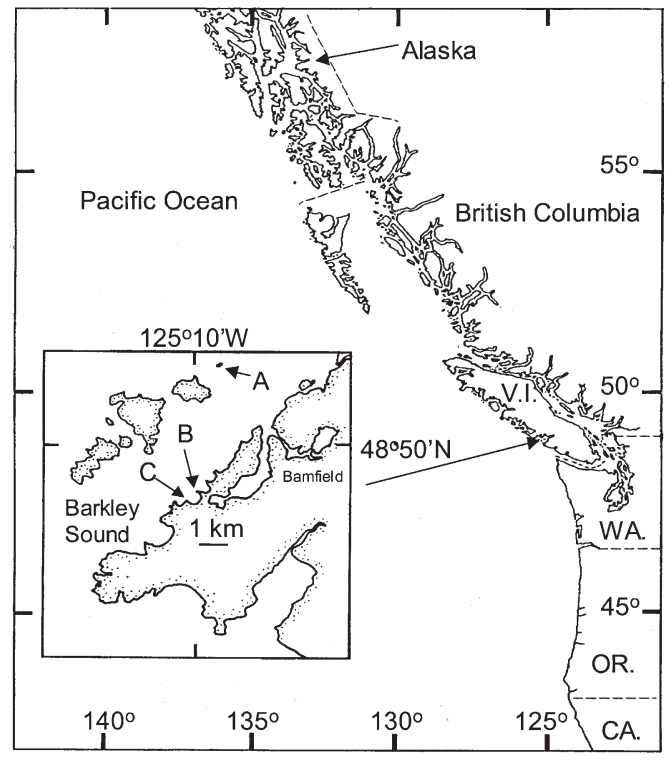

Fig. 1. Locations of transplant sites as well as sites where natural populations were sampled for determining reproductive blade lengths ( $\mathrm{A}=$ Wizard Rocks, $\mathrm{B}=$ Prasiola Point, $\mathrm{C}=$ Nudibranch Point). The high wave impact transplant site was located at Prasiola Point; the sheltered transplant site was at Wizard Rocks. A natural population of Mazzaella splendens was sampled at Wizard Rocks and $M$. linearis was sampled from the other 2 sites

and $0.25 \mathrm{~m}^{2}$ quadrats were placed at each position. Within each quadrat, the longest blade from each holdfast was removed, air dried, and sealed in a plastic bag. The reproductive condition (i.e. spermatangial, carposporangial, tetrasporangial) of each thallus, its length, and overall condition (i.e. entire margins, broken blade, or only stipe/apophysis remaining) were recorded in the laboratory after rehydrating in seawater for $15 \mathrm{~min}$. We chose $5.0 \mathrm{~cm}$ as the break point

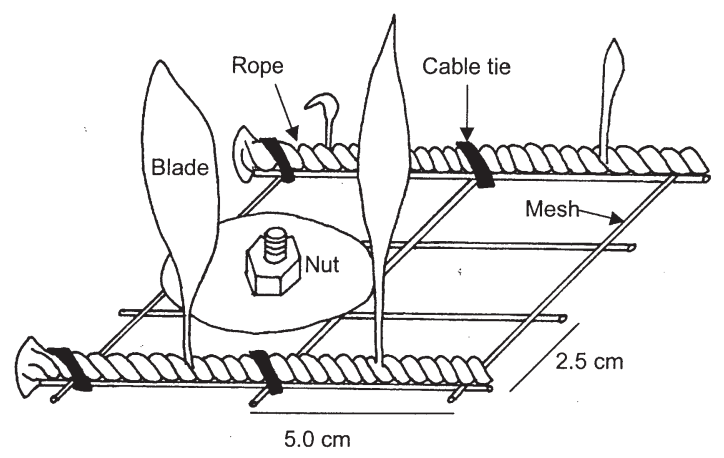

Fig. 2. Illustration of a section of an assembled mesh strip used for transplanting genets of Mazzaella splendens and M. linearis into control and experimental environments 
Table 1. Minimum and mean lengths of reproductive blades sampled from natural populations of Mazzaella splendens and $M$. linearis. Only blades with entire, complete margins are included. Each species was sampled 10 times $(35 \times$ $0.25 \mathrm{~m}^{2}$ quadrats/time) between May 1990 and October 1991 (see Fig. 1 for sites sampled)

\begin{tabular}{|lccc|}
\hline Species & $\begin{array}{c}\text { Minimum } \\
\text { length }(\mathrm{cm})\end{array}$ & $\begin{array}{c}\text { Mean length } \\
(\mathrm{cm})\end{array}$ & $\begin{array}{c}\text { Sample } \\
\text { size }\end{array}$ \\
\hline M. splendens & & & \\
$\begin{array}{l}\text { Spermatangial } \\
\text { Carposporangial }\end{array}$ & 8.5 & 16.7 & 102 \\
Tetrasporangial & 3.6 & 16.8 & 112 \\
M. linearis & & 16.6 & 308 \\
$\begin{array}{l}\text { Spermatangial } \\
\text { Carposporangial }\end{array}$ & 5.0 & 16.5 & 135 \\
Tetrasporangial & 3.5 & 16.5 & 185 \\
& & 16.2 & 641 \\
\hline
\end{tabular}

between SC1 and SC2 because, for both species, this was about the average minimum length found for reproductive blades (Table 1 ). Only blades with entire margins were used in this calculation as their true lengths could be measured with confidence. Although the sampling was biased to the longest blade per holdfast, shorter reproductive blades could not have been found because the first $5.0 \mathrm{~cm}$ or more of these blades is occupied by stipe and apophysis tissue that never becomes reproductive (Shaughnessy 1996).

Transplanted holdfasts, each initially with at least 2 blades of the same size class, were cut in half and trimmed so that a half with one undamaged (i.e. no holes, entire margins) blade was randomly assigned to a control replicate, and the other half to an experimental replicate. Thus, for each species, control and experimental environments contained matched genotypes. Individuals were identified as gametophytes or sporophytes using either reproductive structures or, if vegetative, the resorcinol method as described by Garbary $\&$ De Wreede (1988). There were similar numbers of each phase within a mesh strip.

Trimmed holdfasts were placed $5.0 \mathrm{~cm}$ apart into twists of $9.4 \mathrm{~mm}$ polypropylene rope that had one end already attached to the mesh strip with an electrician's cable tie. After each holdfast with blade was inserted, twists were tightened and followed by another cable tie. Genets could therefore be reliably identified by position. The completed mesh strip population therefore contained 2 parallel strips of rope loaded with genets of both size classes; size class positions were randomly assigned. Control and experimental environments for Mazzaella linearis and M. splendens initially each had 4 mesh strips; however, a wave swept away the fourth $M$. splendens mesh strip as it was being attached. Positions of mesh strip populations within a site were randomly assigned. The intertidal elevation for each replicate population was measured on 2 separate occasions during the summer of 1991.

Monitoring of genets and blades. The experiment commenced May 17, 1991 and was assessed up to 5 additional times (i.e. May 18, 1991; June 13, 1991; August 11, 1991; June 3, 1992; and October 25, 1992). Control Mazzaella linearis and experimental M. splendens could not be enumerated during October 1992 due to the high probability of investigator mortality. At each of the above times, the presence/absence of each genet was checked. Survivors were classified as being in 1 of 3 categories: holdfasts if stipes or blades $>0.5 \mathrm{~cm}$ long were not present, or the longest blade was scored as either SC1 or SC2. Blades were also described as being either broken or having entire margins. Wave swells did not allow enough time for identification of reproductive structures in the high impact common garden. The reproductive status of experimental genets was recorded from the sheltered common garden only during the final day of sampling. On June 13, 1991 it was observed that many blades of experimental $M$. linearis became an abnormal yellow/green color. These blades were designated as bleached and the number of bleached blades in the entire experiment was counted on June 13, 1991.

To test the 3 hypotheses about blade survivorship in particular size classes, it was necessary to follow blade cohorts in each size class. As there was not a satisfactory way of labeling individual blades at the high impact site, the only way to ensure that the same blade was being followed through time was to monitor cohort survival for a relatively short period of time. Cohort monitoring was possible through Day 27, but after this time there is the possibility that an original SC1 blade was lost and replaced by another SC1 blade. To determine if patterns of cohort survival were paralleled by population abundance over a longer period of time, the numbers of blades in each size class were also counted for the entire experiment. Changes in the abundance of a size class could be due to (1) the loss of genets, (2) the loss of all blades and regrowth from holdfasts, (3) SC2 blades becoming SC1 blades by breakage, or (4) SC1 blades becoming SC2 blades by growth. Most blades during the second year of the study were probably regenerated from the same holdfasts, as field observations indicated that the original blades were unlikely to survive the winter.

Assessment of the most frequent break location also required the tracking of blade cohorts and so this analysis was restricted to the first $27 \mathrm{~d}$ as well. This comparison was restricted to SC2 blades of each species, and comparisons were only made within a treatment. A SC2 blade that became a holdfast identified a junction break, and a SC2 blade that became a broken SC1 blade indicated a blade break. 
Statistics. Genet survival for each treatment was analyzed using the non-parametric Cox regression (Lee 1992) procedure as performed by SPLUS (StatSci., Seattle, WA). The dependent variable was the time of each individual until death, and independent variables were species (Species: Mazzaella splendens and $M$. linearis), environment (Env.; control and experimental), and the interaction Species $\times$ Env.: Size class and life history phases were not used in the model because sample sizes were too small for these data subsets. Data were right-censored (i.e. some individuals were still alive at the end of the experiment) and Cox regression used this information in the analysis. Data must be independent for Cox regression and this assumption was met because responses of holdfasts after splitting were measured. Kaplan-Meier (K/M) survivorship curves (Lee 1992) with non-parametric 95\% confidence intervals were calculated by SPLUS on logtransformed data from each treatment. K/M graphs are often presented as a stepped curve but we used a smoothed curve to more easily see the confidence interval for each treatment and time. The remaining analyses were performed with SYSTAT (V.7). The Mann-Whitney $U$-test was used to compare the \% of cohort survivors in different size classes, as well as the number of blades in different size classes, and the \% of genets failing at junctions versus within blades; no comparisons were made for time 0.0. Comparisons between intertidal elevations and the condition of genets were done graphically as there were not enough replicate populations to have confidence in a correlation analysis.

\section{RESULTS}

Survivorship of control and experimental Mazzaella splendens genets differed whereas this was not the case for M. linearis (Table 2, Fig. 3). The effect of environment on genet survival was more pronounced for $M$. splendens than for $M$. linearis. During the first $24 \mathrm{~h}$ of the study, genets of experimental $M$. splendens experienced a lower rate of survival than for control M. splendens (Fig. 3A). Beyond this early time, the 2 treatments showed similar rates of survival. In contrast, survival rates of experimental and control $M$. linearis genets were similar until the end of the study (Fig. 3B). A comparison of genet survivorship at the high wave impacted site versus the sheltered site indicates that survival during the first $54 \mathrm{~d}$ was lowest at the high wave impact site, regardless of species (Fig. 3).

At the high wave impact site, survivorship of the control SC2 Mazzaella linearis blade cohort was significantly greater than for the $\mathrm{SC} 2$ experimental M. splendens cohort during the first $27 \mathrm{~d}$, and during this time
Table 2. Summary of Cox regression for time until death of genets in common gardens with independent variables Species (Mazzaella splendens and M. linearis) and Env. (control and experimental). Coef. $=$ coefficient, $\operatorname{Exp}=$ exponential, Env. = environment, $z=\mathrm{z}$ score, $\mathrm{p}=$ probability, critical $\alpha=0.05$

\begin{tabular}{|lrrrc|}
\hline $\begin{array}{l}\text { Independent } \\
\text { variable }\end{array}$ & Coef. & $\operatorname{Exp}($ coef.) & $z$ & $\mathrm{p}$ \\
\hline Species & & & & \\
Env. & -0.0114 & 0.989 & -0.214 & 0.083 \\
Species $\times$ Env. & -0.2379 & 1.269 & 4.478 & 0.000 \\
& & 0.784 & -4.297 & 0.000 \\
\hline
\end{tabular}
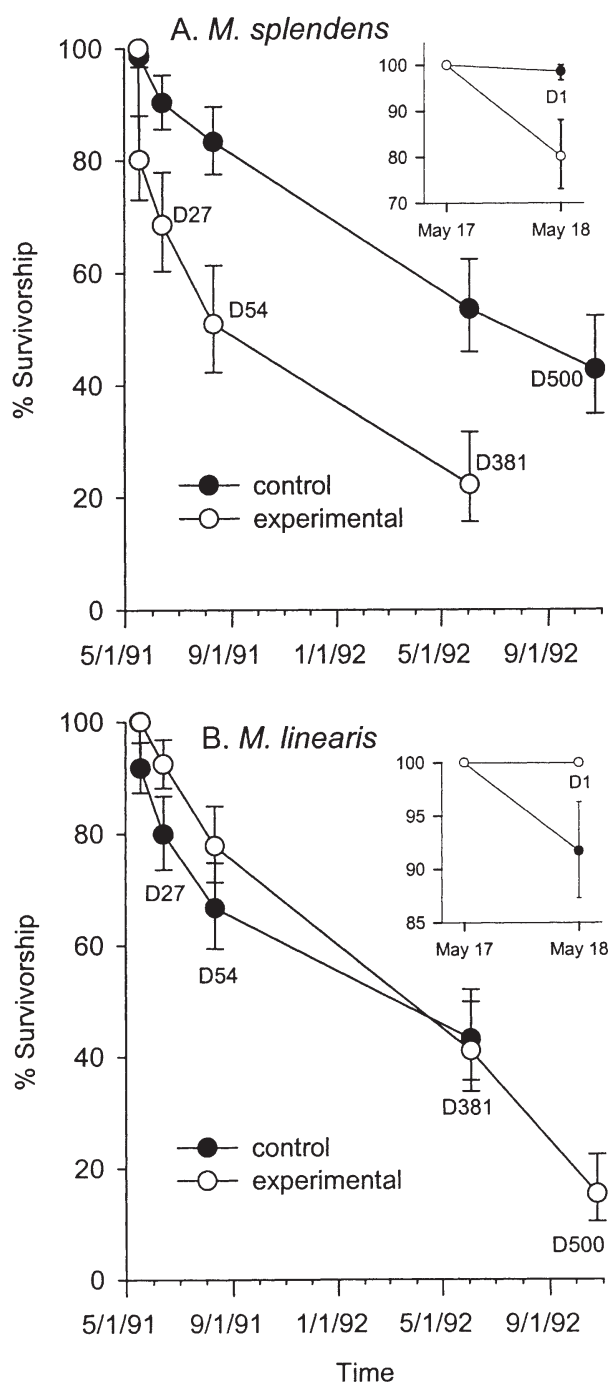

Fig. 3. Comparison of treatment responses for median (error bars represent $95 \%$ confidence interval) \% survivorship of individual genets of (A) Mazzaella splendens and (B) M. linearis. $\mathrm{n}$ is usually 4 populations per treatment; D27 = Day 27, etc. Inset graphs clarify results by the end of Day 1. Dates given as mo/d/yr 

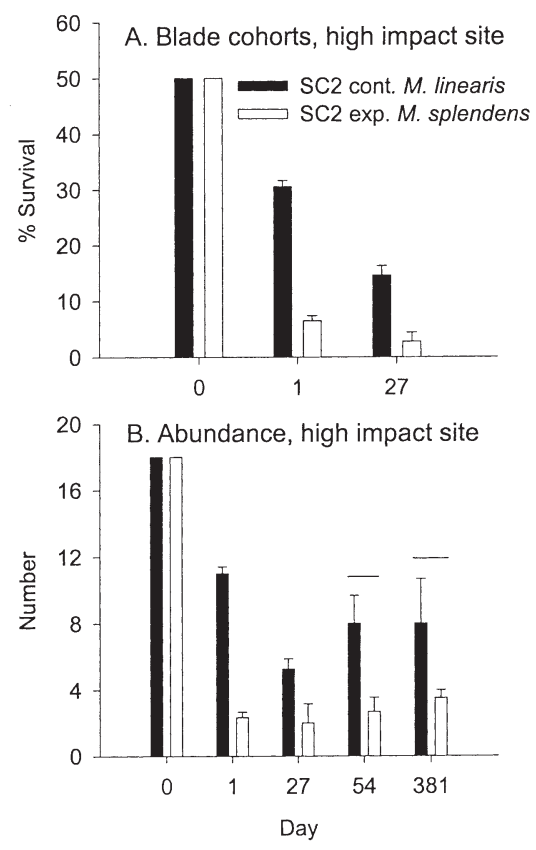

Fig. 4. (A) Mean \% cohort survival and (B) population abundance at the high wave impact site for SC2 control Mazzaella linearis and SC2 experimental M. splendens (\% of original number of blades per SC). A horizontal line over treatment comparisons indicates a non-significant Mann-Whitney $U$ test; critical $\alpha=0.05 ; \mathrm{n}$ is usually 4 populations per treatment; error bars are standard error
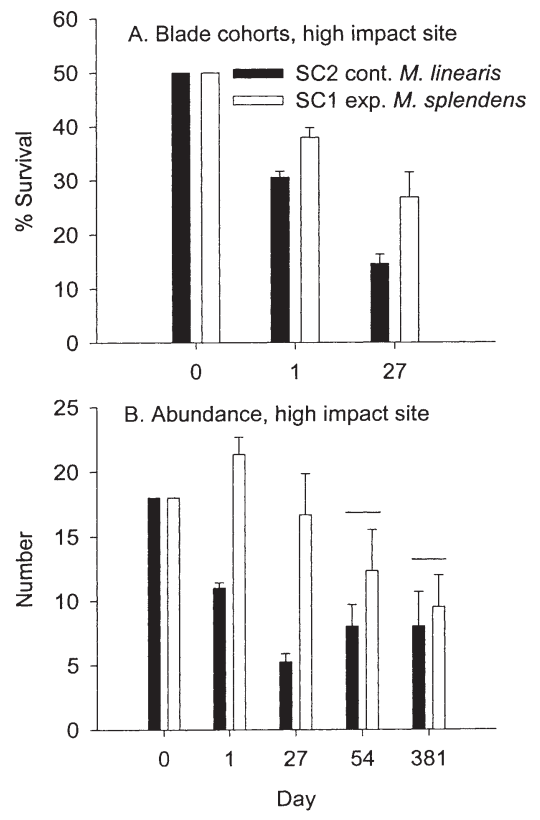

Fig. 5. (A) Mean \% cohort survival and (B) population abundance at the high wave impact site for SC2 control Mazzaella linearis and SC1 experimental M. splendens (\% of original number of blades per SC). A horizontal line over treatment comparisons indicates a non-significant Mann-Whitney $U$ test; critical $\alpha=0.05$; $\mathrm{n}$ is usually 4 populations per treatment; error bars are standard error the abundance of SC2 blades for these same treatments followed the same pattern (Fig. 4A,B). Beyond Day 27 , the abundance of $\mathrm{SC} 2$ for both treatments increased but did not significantly differ; the increase was due to $\mathrm{SC} 1$ blades growing into the SC2 category. At the same site, survivorship of the SC1 experimental M. splendens cohort was significantly greater than the SC2 control M. linearis cohort (Fig. 5A). Changes in abundance during the first $27 \mathrm{~d}$ also demonstrated this pattern, but size class numbers were similar beyond this time (Fig. 5B). Increases in the abundance of control SC2 M. linearis were due to SC1 blades growing into SC2.

At the sheltered site, Day 1 survivorship of the SC2 experimental Mazzaella linearis blade cohort was significantly greater, but only marginally so, than that of the SC2 control M. splendens cohort (Fig. 6A). Survivorship for these cohorts did not differ by Day 27 . This pattern also occurred at the level of the population during Days 1 and 27, and abundance was similar during the remaining days except for Day 381, when there were significantly more SC2 control M. splendens blades (Fig. 6B). The increase of the latter blades on Day 381 was due to growth from SC1 into SC2.

Genet bleaching did not occur for either species within the high wave impact transplant site (data not presented). Within the sheltered site, Mazzaella linearis had the stronger positive relationship between
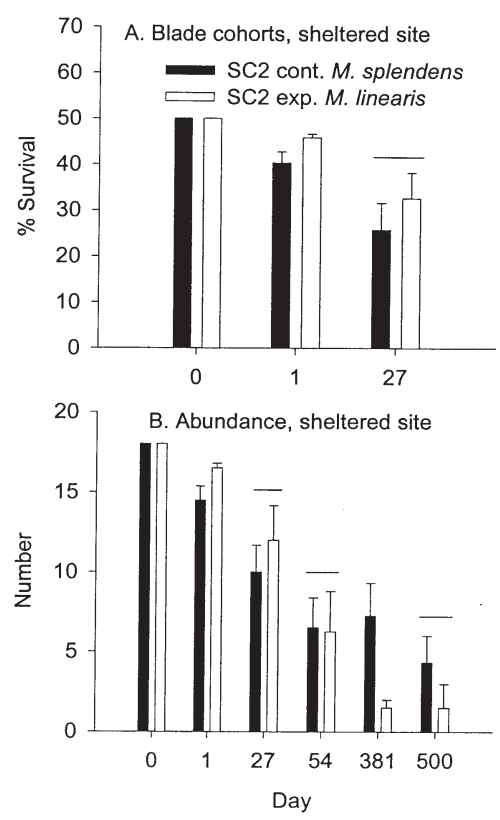

Fig. 6. (A) Mean \% cohort survival and (B) population abundance at the wave-sheltered site for SC2 control Mazzaella splendens and SC2 experimental $M$. linearis (\% of original number of blades per SC). A horizontal line over treatment comparisons indicates a non-significant Mann-Whitney $U$ test; critical $\alpha=0.05 ; \mathrm{n}$ is usually 4 populations per treatment; error bars are standard error 

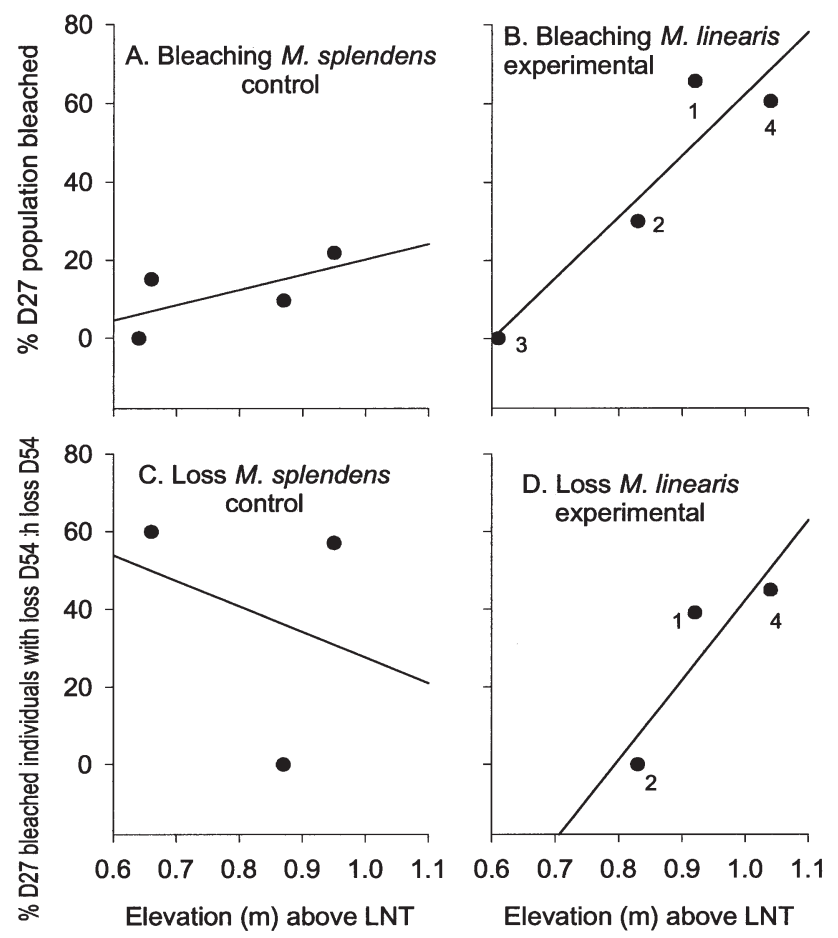

Fig. 7. Relationships between the intertidal elevation of a mesh strip population $(\mathrm{A}, \mathrm{B})$ and the \% of genets with bleached blades within that population on Day 27 (D27), and the same elevations $(C, D)$ correlated to the \% of individuals in each population that were bleached on D27 and either gone or reduced in size by Day 54 (D54). Note dropping of 2 populations that showed $0.0 \%$ bleaching in $(\mathrm{A}, \mathrm{B})$. Number labels next to points in (B,D) are the same as population numbers in Fig. 8; fit lines are for clarity. LNT: Lowest Normal Tide

intertidal elevation and the percent of a population that was bleached (Fig. 7B). A positive relationship also existed between elevation versus the number of M. linearis individuals that had bleached blades on Day 27 and were either gone or had lost biomass by Day 54 (Fig.7D). The same comparisons with elevation for control M. splendens were weak (Fig. 7A,C). Experimental $M$. linearis population 3, which occurred in the lowest intertidal position for this treatment and did not bleach (Fig. 7B), also demonstrated higher genet survivorship and $\mathrm{SC} 2$ abundance than the other 3 populations in this treatment (Fig. 8).

For SC2 Mazzaella splendens cohorts during Day 1, the $\%$ of failures at the junction versus within blades did not significantly differ for control genets, but blades showed significantly greater failure than junctions in the experimental treatment (Fig. 9A). By Day 27, a significantly higher \% of control blades had failed, but failure rates for the junction and blade did not differ for the experimental treatment (Fig. 9A). For $\mathrm{SC} 2 \mathrm{M}$. linearis cohorts, control genets broke significantly more often in blades during Day 1 , but junction failures were more common for experimental genets during this time (Fig. 9B). Failure rates within treatments were not significantly different on Day 27.

\section{DISCUSSION}

Biomechanical models of blade survivorship for red algae have generated a variety of predictions that need to be field tested. Our objectives were therefore to use a transplant experiment to evaluate a series of hypotheses about genet and blade survivorship for Mazzaella splendens and M. linearis, as well as a separate hypothesis about where in the genet tissue failure should occur for these species. The following discussion addresses survivorship predictions relevant to the high wave impact site first, followed by those for the sheltered site, and then the tissue failure hypothesis is considered.

Genets of Mazzaella splendens at the high wave impact site did not survive as well as those of the native $M$. linearis. Of the $M$. splendens genets lost
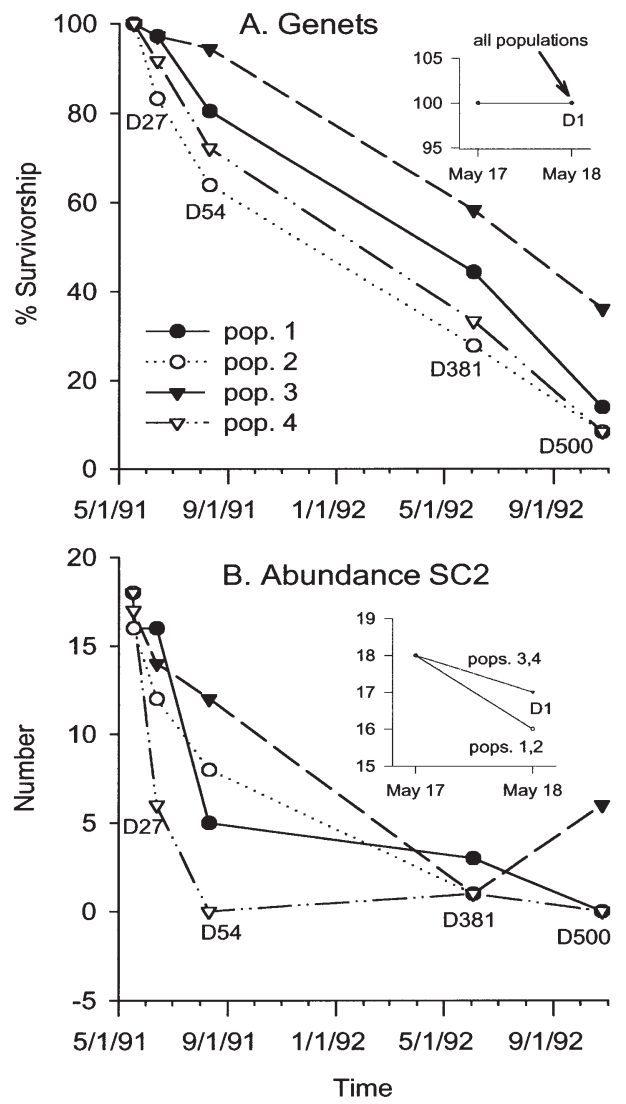

Fig. 8. (A) \% survivorship for each population of Mazzaella linearis genets in the sheltered transplant site, and (B) abundance of SC2 $M$. linearis blades for each population at this site. Inset graphs clarify results by the end of Day 1. D1 = Day 1, etc. Dates given as mo/d/yr 

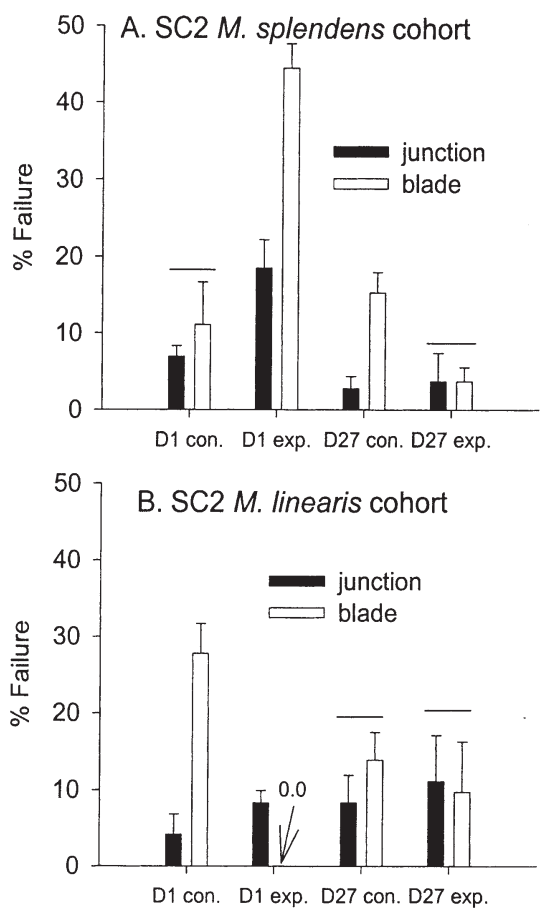

Fig. 9. (A) Mean \% of failures at the junction versus the blade for cohorts of SC2 Mazzaella splendens, and (B) SC2 M. linearis $\left(\mathrm{D} 1 \mathrm{=}\right.$ Day 1 , etc $;$ con. $=$ control $_{\text { }}$ exp. $=$ experimental ; horizontal line within treatment comparisons indicates a nonsignificant result using a Mann-Whitney $U$-test; critical $\alpha=$ $0.05 ; \mathrm{n}$ is usually 4 populations per treatment; error bars are standard error

during the first day, most had long blades and so blades with holdfasts were pulled free from the tight twists of the rope by hydrodynamic forces. There were no other sources of mortality present that could have acted so quickly. After Day 1, experimental M. splendens genets were not as vulnerable to hydrodynamic removal from the rope since long blades had either failed at the junction, or long blades were reduced to short, broken blades. Hydrodynamic forces had the same shortening effect on long genets of Fucus gardneri Silva transplanted from a sheltered to a high wave impact site (Blanchette 1997). The fact that initial rates of genet survival for control $M$. linearis were generally higher is due to its narrower blades that decrease the hydrodynamic load on holdfasts.

Both species showed similar rates of genet survivorship after Day 1 in the high wave impact common garden. Mazzaella splendens and $M$. linearis appear to be similarly vulnerable to overgrowth competition from the barnacle Polycipes polymerus and mussel Mytilus californianus, which were encroaching and recruiting on to mesh strips by Day 54. On the last day that the experiment could be monitored at this site, Day 381, about $50 \%$ of each replicate population was covered by these invertebrates. Both of these invertebrates are competitive dominants within high wave impact communities, where they encroach and eventually dominate patches of algae of short stature (Paine \& Levin 1981, Paine 1984). Despite the ability of M. linearis to produce a large holdfast with many blades (Abbott 1971), and its long stipe that raises the blade well above the substratum, $M$. linearis genets were eventually smothered by these sessile invertebrates.

Blade survivorship within the high impact site was as predicted by the biomechanics model for the 2 species (Shaughnessy et al. 1996). More long blades from the control Mazzaella linearis cohort survived than did long blades from the experimental $M$. splendens cohort. M. linearis did not always have a greater number of long blades when population abundance was considered, but all of the long M. splendens blades that did persist were broken and barely cleared the $5.0 \mathrm{~cm}$ length needed to be classified in the long, potentially reproductive size class. Blades of experimental $M$. splendens that started off being short survived better than long blades of control $M$. linearis as predicted. All of the short M. splendens blades, including both those that started in the short size class and those that became short by breakage, were able to survive at least as well as long $M$. linearis blades because junction break forces do not differ between the species, and the lower surface area of short blades means they experience reduced hydrodynamic forces (Shaughnessy et al. 1996).

Although short entire or broken blades of Mazzaella splendens can survive at the high impact site of $M$. linearis, very few short $M$. splendens blades from natural populations are reproductive, regardless of whether the genet is spermatangial, carposporangial, or tetrasporangial. $M$. splendens also does not have the developmental option of making its blade narrower like those of $M$. linearis in order to reach a length necessary for reproduction. Blades of M. splendens actually become wider when regrown at a high impact site with M. linearis (Shaughnessy 1994). Thus, the ability of $M$. linearis to produce longer, potentially reproductive blades within a high impact site is still greater than for $M$. splendens within this kind of site.

In the sheltered transplant site, rates of genet survivorship over $381 \mathrm{~d}$ were similar between Mazzaella splendens and $M$. linearis. From a hydrodynamic perspective, it is not surprising that genets of $M$. linearis initially survived so well in the sheltered site. The lower surface area of its blades means that its holdfasts were less likely to be pulled from the rope than those of $M$. splendens. Even though genet survival within the sheltered site was similar for the 2 species, differences in physical appearance between them, as well as the condition of those individuals which died, suggest 
that the primary sources of mortality differed between the species.

Genets of Mazzaella linearis in the sheltered site had a bleached yellow-green appearance with ragged blades, and this condition was more common for replicate populations higher in the intertidal zone. In natural populations, genets of $M$. linearis are rarely bleached; they are dark purple as they were for control genets of $M$. linearis in our high impact transplant site. In contrast, by mid-summer it is common to find natural populations of $M$. splendens with some partially yellow/green genets in the upper half of this species' low intertidal distribution. Other higher intertidal species of $M$. also demonstrate seasonal bleaching at least at the tips of fronds (Scrosati \& DeWreede 1998). Several factors can lead to algal bleaching and could be responsible for this condition of $M$. linearis genets in the sheltered transplant site. These include higher irradiance due to lack of shading, potentially lower nitrate levels due to less mixing events during the summer, a disruption of nutrient uptake by higher levels of desiccation, and a thicker blade (Waaland et al. 1974, Gerard \& Mann 1979, Thomas et al. 1987, Gantt 1990, Hurd \& Dring 1991, Beach \& Smith 1996, Hurd et al. 1996). We consider the bleaching of $M$. linearis to indicate physiological damage, unlike for $M$. splendens, because $M$. linearis genets from natural populations do not demonstrate the degree of bleaching demonstrated by $M$. linearis experimental genets, and bleached individuals of $M$. linearis in our experiment were more likely to die or lose biomass. Unlike the higher intertidal populations of $M$. linearis at the sheltered site, the lowest population for this species contained no bleached genets. Genets in this location should have had the most shading, the most access to nutrients, and the least desiccation.

While genets of Mazzaella linearis are apparently vulnerable to abiotic conditions within a sheltered site, factors other than physiological stress were probably responsible for the loss of $M$. splendens genets within the sheltered transplant site. Although a positive relationship existed between elevation and the percent of M. splendens genets with bleaching, there was a weak relationship between the percent of $M$. splendens genets that lost blades or died versus elevation. This suggests that sources of mortality to M. splendens are not directly linked to its bleaching. In addition to always being more vulnerable to hydrodynamic removal relative to $M$. linearis, $M$. splendens is competitively inferior to kelps (Hruby 1976, as Iridaea cordata). In the lower half of the sheltered common garden, sweeping, shading, and holdfast overgrowth by the kelps Alaria marginata Postels et Ruprecht, Laminaria setchelli Silva, and particularly Egregia menziesii may have killed control M. splendens genets as well as genets from the one healthy, low intertidal population of experimental $M$. linearis. Thus, the most common source of mortality to $M$. linearis was probably related to physiological stress, whereas drag forces and interspecific competition from kelps may have killed most $M$. splendens genets.

The pattern of blade survival in the sheltered site was not as predicted by the biomechanics model. Blade cohorts of experimental Mazzaella linearis and control M. splendens had similar rates of survival over the first $27 \mathrm{~d}$, rather than demonstrating a greater rate of survival for $M$. linearis blades. This is because the abiotic stresses that are probably damaging $M$. linearis in a sheltered site were not a component of the biomechanics model; these stresses acting on genets of $M$. linearis may also have lowered blade survival to the level demonstrated by $M$. splendens blades. The same stresses may also be the reason why $M$. linearis, despite its ability retain some long, potentially reproductive blades, demonstrated almost no actual reproductive structures when destructive sampling occurred on the last day of monitoring. More reproductive structures were observed in long control $M$. splendens blades on the last day of the experiment. Given that $M$. splendens appeared much less stressed, and that it has a wider blade than $M$. linearis, the reproductive potential of $M$. splendens is greater than $M$. linearis within a sheltered site.

Previous studies with the red algae Mastocarpus, Mazzaella splendens, and $M$. linearis indicate that the most frequent break location should be the junction (Carrington 1990, Shaughnessy et al. 1996). This prediction was generally not supported in our present study since, for both species, break frequencies were either more common in the blade than the junction, or the 2 locations had similar break frequencies. Previous work with these algae used undamaged blades since the focus of these studies was to understand the relationship between functional morphology and survivorship. In our present study, blades also started out being undamaged, but wounds inflicted during the first $24 \mathrm{~h}$ at the high impact site from the surrounding gooseneck barnacle Polycipes polymerus and mussel Mytilus californianus may have disrupted tissue integrity enough so that the weak point was now in the blade. Similarly, sharp wounds to blades of the closely related Mazzaella flaccida (Setchell et Gardner) Fredericq result in the rapid loss of brittle blades unless there is time for rounding of the wound (Denny et al. 1989, as Iridaea flaccida). Reasons why junction breaks were not more frequent in the sheltered transplant site are unclear as blades also started off being entire, but barnacles and gastropods were uncommon.

The previous biomechanics model about Mazzaella splendens and $M$. linearis and the present transplant 
experiment indicate that morphological and biomechanical properties of $M$. linearis genets are paramount for allowing it to survive long enough to produce potentially reproductive blades. The narrow blade of $M$. linearis puts the holdfast and the blade itself at less risk from drag, and the capacity to produce a blade long enough to be reproductive must be a critical attribute in maintaining a population because holdfasts are eventually smothered by barnacles and mussels. These 2 studies also reveal that the apparently greater physiological tolerance of the wide bladed form of $M$. splendens may be more important than morphology in facilitating its survival in sheltered sites. The lack of inclusion of data about physiological optima of the 2 species is therefore why the biomechanics model by Shaughnessy et al. (1996) did not successfully predict blade survival within the sheltered transplant site. Our result where the junction was rarely the most frequent break location is also inconsistent with the current understanding of how the junction functions in red algae like Mazzaella. This functional explanation needs to be refined so that the sources and timing of tissue damage are considered.

Acknowledgements. This work could not have been completed without the intrepid field assistance of Put Ang, Pat Ewanchuk, Jeong Ha Kim, Sally Leys, Nelson Lauzon and Brent Phillips. They survived. The manuscript benefited from reviews by Sharyn Marks and anonymous reviewers. The study was funded by Rob De Wreede's grant from the Natural Sciences and Engineering Research Council of Canada (No. 5-89872). We thank the Huu-Ay-Aht First Nations for allowing us access to study sites.

\section{LITERATURE CITED}

Abbott IA (1971) On the species of Iridaea (Rhodophyta) from the Pacific coast of North America. Syesis 4:51-72

Beach KS, Smith CM (1996) Ecophysiology of tropical rhodophytes. I. Microscale acclimation in pigmentation. J Phycol 32:701-10

Bell EC (1999) Applying flow tank measurements to the surf zone: predicting dislodgment of the Gigartinaceae. Phycol Res 47:159-166

Blanchette CA (1997) Size and survival of intertidal plants in response to wave action: a case study with Fucus gardneri. Ecology 78:1563-1578

Carrington E (1990) Drag and dislodgment of an intertidal macroalga: consequences of morphological variation in Mastocarpus papillatus Kützing. J Exp Mar Biol Ecol 139: $185-200$

Denny MW (1995) Predicting physical disturbance: mechanistic approaches to the study of survivorship on wave-swept shores. Ecol Monogr 65:371-418

Denny MW, Daniel TL, Koehl MAR (1985) Mechanical limits to size in wave-swept organisms. Ecol Monogr 55:69-102
Denny MW, Brown V, Carrington E, Kraemer GA, Miller A (1989) Fracture mechanics and the survival of wave-swept macroalgae. J Exp Mar Biol Ecol 127:211-28

Dudgeon SR, Johnson AS (1992) Thick vs thin: thallus morphology and tissue mechanics influence differential drag and dislodgment of two co-dominant seaweeds. J Exp Mar Biol Ecol 165:23-43

Gantt E (1990) Pigmentation and photoacclimation. In: Cole KM, Sheath RG (eds) Biology of the red algae. Cambridge University Press, Cambridge, p 203-219

Garbary DJ, DeWreede RE (1988) Life history phases in natural populations of Gigartinaceae (Rhodophyta): quantification using resorcinol. In: Lobban CS, Chapman DJ, Kremer BP (eds) Experimental phycology: a laboratory manual. Cambridge University Press, New York, p $174-178$

Gerard VA, Mann KH (1979) Growth and production of Laminaria longicruris (Phaeophyta) populations exposed to different intensities of water movement. J Phycol 15:33-41

Hommersand MH, Guiry MD, Fredericq S, Leister GL (1993) New perspectives in the taxonomy of the Gigartinaceae (Gigartinales, Rhodophyta). Hydrobiologia 260/261: 105-120

Hruby T (1976) Observations of algal zonation resulting from competition. Estuar Coast Mar Sci 4:231-233

Hurd CL, Dring MJ (1991) Desiccation and phosphate uptake by intertidal fucoid algae in relation to zonation. Br Phycol J 26:327-333

Hurd CL, Harrison PJ, Druehl LD (1996) Effects of seawater flow velocity on inorganic nitrogen uptake by morphologically distinct forms of Macrocystis integrifolia from wavesheltered and exposed sites. Mar Biol 126:205-214

Koehl MAR (1986) Seaweeds in moving water: form and mechanical function. In: Givinish TJ (ed) On the economy of plant form and function. Cambridge University Press, Cambridge, p 603-634

Lee ET (1992) Statistical methods for survival data analysis, 2nd edn. John Wiley \& Sons, Inc., New York

Paine RT (1984) Ecological determinism in the competition for space. Ecology 65:1339-1348

Paine RT, Levin SA (1981) Intertidal landscapes: disturbance and the dynamics of pattern. Ecol Monogr 51:145-178

Scrosati R, DeWreede RE (1998) The impact of frond crowding on frond bleaching in the clonal intertidal alga Mazzaella cornucopiae (Rhodophyta, Gigartinaceae) from British Columbia, Canada. J Phycol 34:228-232

Shaughnessy FJ (1994) Population differentiation of two sympatric species of red algae, Mazzaella splendens and Mazzaella linearis, in Barkley Sound, British Columbia, Canada. PhD thesis, University of British Columbia, Vancouver

Shaughnessy FJ (1996) Identification and microgeographic distribution of Mazzaella splendens and Mazzaella linearis (Gigartinaceae, Rhodophyta). Can J Bot 74:999-1008

Shaughnessy FJ, DeWreede RE, Bell EC (1996) Consequences of morphology and tissue strength to blade survivorship of two closely related Rhodophyta species. Mar Ecol Prog Ser 136:257-266

Thomas TE, Harrison PJ, Turpin DH (1987) Adaptations of Gracilaria pacifica (Rhodophyta) to nitrogen procurement at different intertidal locations. Mar Biol 93:569-580

Waaland JR, Waaland SD, Bates D (1974) Chloroplast structure and pigment composition in the red alga Griffithsia pacifica. J Phycol 10:193-199 